\title{
EVALUATION OF PARKING AREA SPORT ACTIVITIES BASE ON LAND USE NEEDS EDUCATION ACTIVITIES SYSTEM
}

\author{
Juang Akbardin \\ Department of Civil Engineering, \\ Universitas Pendidikan Indonesia, Bandung - Indonesia \\ Corresponding author: akbardien@upi.edu
}

Received: 30 Maret 2019
Revised: 9 April 2019
Article History:

Accepted: 10 April 2019
Available online: 11 April 2019

Abstract: The need for parking space in the land use system for educational activities is needed in line with the growth of vehicle users. Educational areas with a high center of activity really need adequate parking space for ease of accessibility. The center of sports activities in the area of higher education activities requires the ease of using vehicle parking. The system of sports activities in higher education areas with high movement activities requires evaluation of parking space requirements in accordance with the activity system. Analyzing parking space requirements based on system activities is the main objective of this study. Specifically the purpose of the study is based on the analysis of parking duration. The frequency and accumulation of vehicles in the parking area is a characteristic impact of the activity system of sports activities. The analysis method based on parking space units is analyzed based on parking methods with variables that affect vehicle use in the activity system in the sports activity zone. Variables of parking user characteristics are based on survey responses from vehicle users from their activity system. The results showed the existing conditions with 34 units of parking spaces with parking index 1.1764 with the need for parking space of $460 \mathrm{~m} 2$. With a system of high activity and vehicle growth, the parking area needs at the prediction of the next 10 years require an area of 59 parking spaces with a parking index of 0.949 with a parking area of $643.89 \mathrm{~m} 2$. So that the development of the parking area in the sports zone activity system requires an additional parking area of $183,89 \mathrm{~m} 2$.

Keywords - parking evaluation, sports activities, land use, educational activity system, area needs

\section{Introduction}

The development of a system of higher education activities developed rapidly requiring good infrastructure requirements in accordance with the system of activities. The system of higher education zone activities requires alignment with the growth of the mobility system in the activity zone. The center of sports activities is a infrastructure that is very important for the development of education.

The sports activity system that develops competition activities is in desperate need of parking area infrastructure that meets the requirements of the activity system. The growth of vehicle users with high activity causes the needs of the parking zone in sports activities to require an adjustment based on their activity system. The frequency of vehicles with a system of vehicle user activity greatly affects the needs of the parking area. The duration and accumulation of vehicle parking were analyzed based on routine activities at the peak hours of the activity system. The 
purpose of this study is to analyze the parking area requirements on land use education activity systems based on a system of sports activities in universities.

The development of an activity system that is determined based on the frequency of activities with high mobility (Akbardin, 2005; Akbardin, 2013; Akbardin and Putra, 2016) requires infrastructure requirements that are in accordance with the vehicle movement volume based on the activity system (Akbardin, et.al., 2017; Akbardin, et.al., 2018a; Akbardin, et.al., 2018b; Akbardin, et.al., 2018c).

\section{Parking}

Parking is the state of a vehicle that is temporary stopped and the vehicle does not move for a while with the driver did not leave the vehicle (Benenson, I., K. Martens, and S. Birfir., 2008; Beunen, R., C. F. Jaarsma, and H. D. Regnerus. 2006; Bonsall, P., and I. Palmer. 2004; Borgers, A., A. Kemperman, L. Toll, and H. Timmermans. 2010; CROW. 2003; Departemen Perhubungan 1998)

\section{Determination of Parking Space Units (SRP)}

The determination of parking spaces units (SRP) is divided into three kinds of vehicles and based on the determination of SRP for passenger cars are classified into three classes (Benenson, I., K. Martens, and S. Birfir., 2008; Beunen, R., C. F. Jaarsma, and H. D. Regnerus. 2006; Bonsall, P., and I. Palmer. 2004; Borgers, A., A. Kemperman, L. Toll, and H. Timmermans. 2010; CROW. 2003; Departemen Perhubungan 1998). As in Table 1

Table. 1. Determination of Parking Space Units (SRP)

\begin{tabular}{ccc}
\hline \multicolumn{1}{c}{ Category } & Parking Space Unit \\
\hline 1. a. Car passenger Type I & $2,30 \times 5,00$ \\
b. Car passenger Type II & $2,50 \times 5,00$ \\
c. Car passenger Type III & $3,00 \times 5,00$ \\
2. Bus/truck & $3,40 \times 12,50$ \\
3. Motorcycle & $0,75 \times 2,00$ \\
\hline \multicolumn{2}{c}{ (source : parking planning and operating guidelines.1998) }
\end{tabular}

\section{Pattern Parking}

The implemented parking pattern is in accordance with existing conditions in accordance with the needs of the system activity and space capacity (Akbardin, 2005; Akbardin, 2013; Akbardin and Putra, 2016). There are several parking patterns that have developed both in big cities and in small towns (Akbardin, et.al., 2017; Akbardin, et.al., 2018a; Akbardin, et.al., 2018b; Akbardin, et.al., 2018c). The developed parking pattern is as follows:

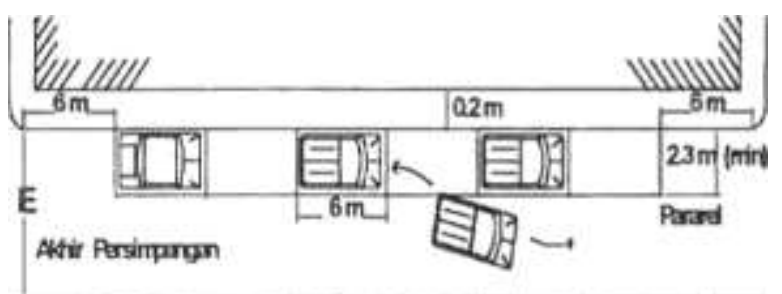

Figure 1 Parallel parking arrangements

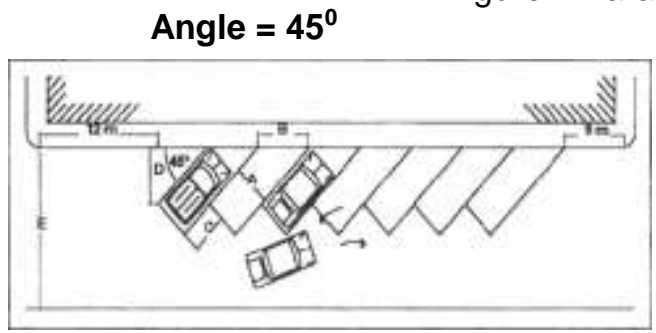

Angle $=90^{\circ}$

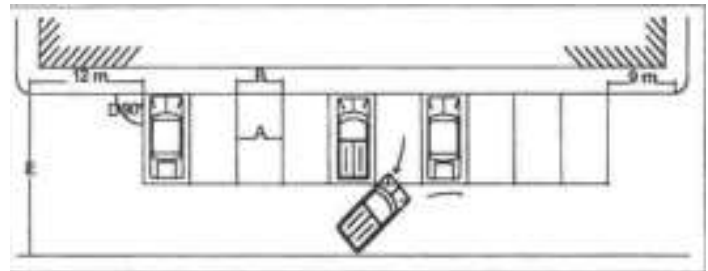

Figure 2 The parking procedure forms of the angle $45^{\circ}$ and $90^{\circ}$ 


\section{Methodology}

This research approach from the study of the parking user behavior characteristics toward the accessibility of the center location for non commercial activities by estimating the related variables of the non-commercial parking activity system on UPI campus. The method used in this study is a spaciousness survey with data collection through the questionnaire design. The utilise of this method has done to determine the research variables used (Akbardin, et.al., 2017; Akbardin, et.al., 2018a; Akbardin, et.al., 2018c; Guan, H., X. Sun, X. Liu, and L. Liu. 2005;

The used research variables are:

- Volume of incoming and outgoing vehicles

- The duration of the vehicle

- Parking user

- Parking capacity

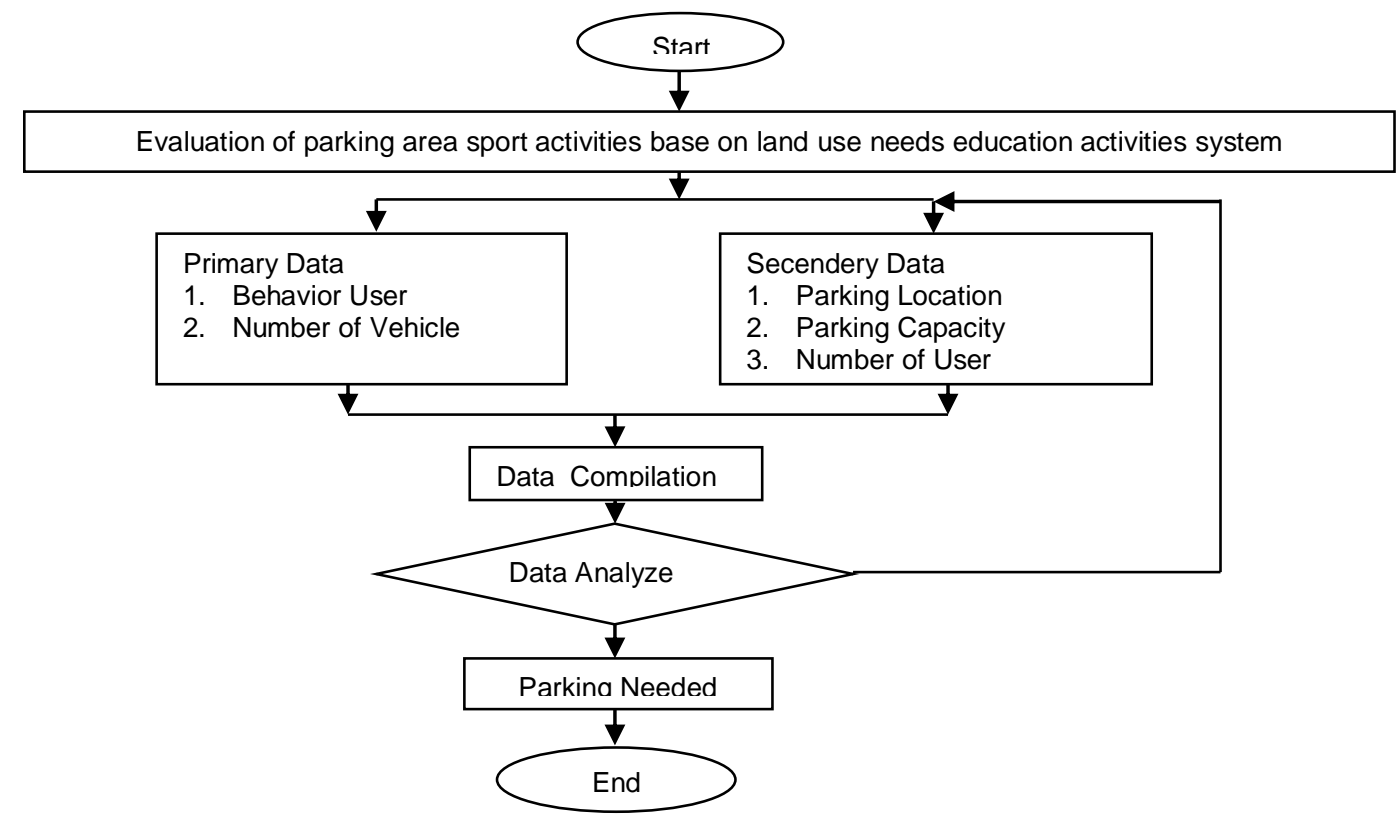

Figure. 3. Research Flow Chart

\section{Result and Discussion}

\section{Analysis existing conditions parking area}

Existing conditions are parked in the center of sports activities with a parking area

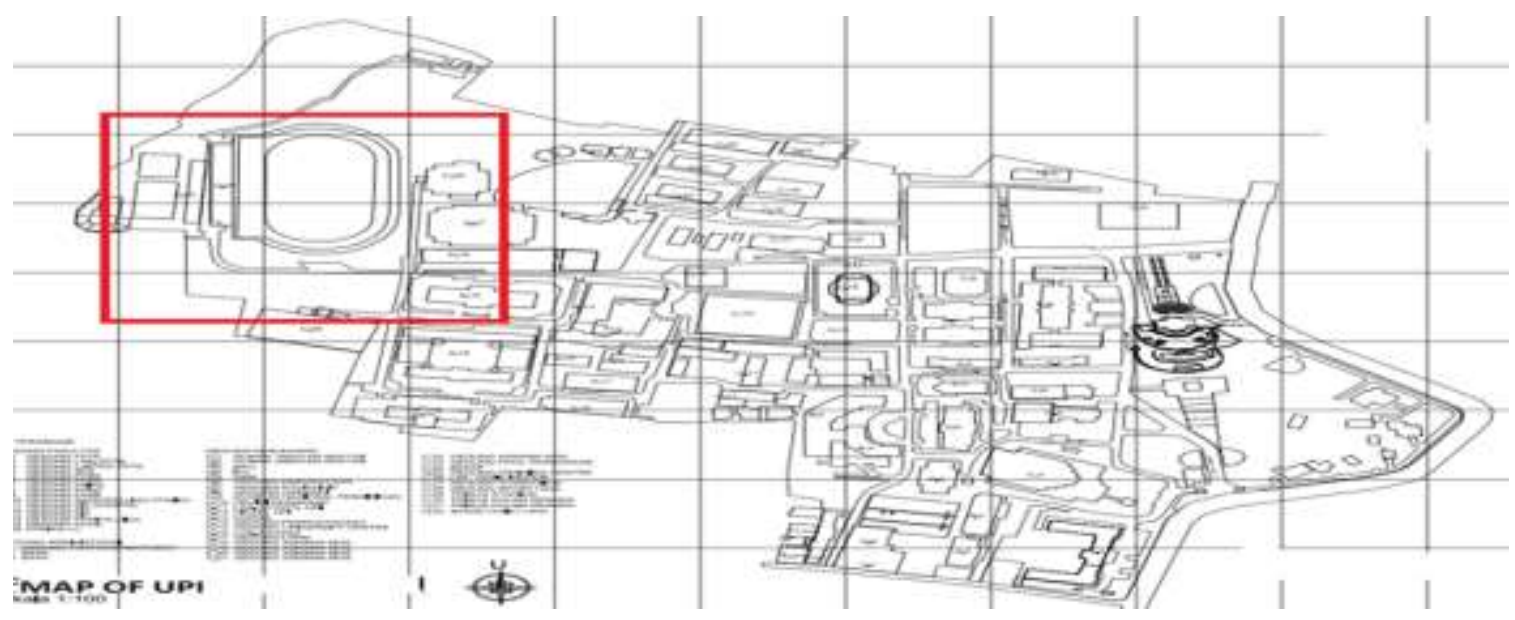

Figure. 4. Map of UPI land Use 

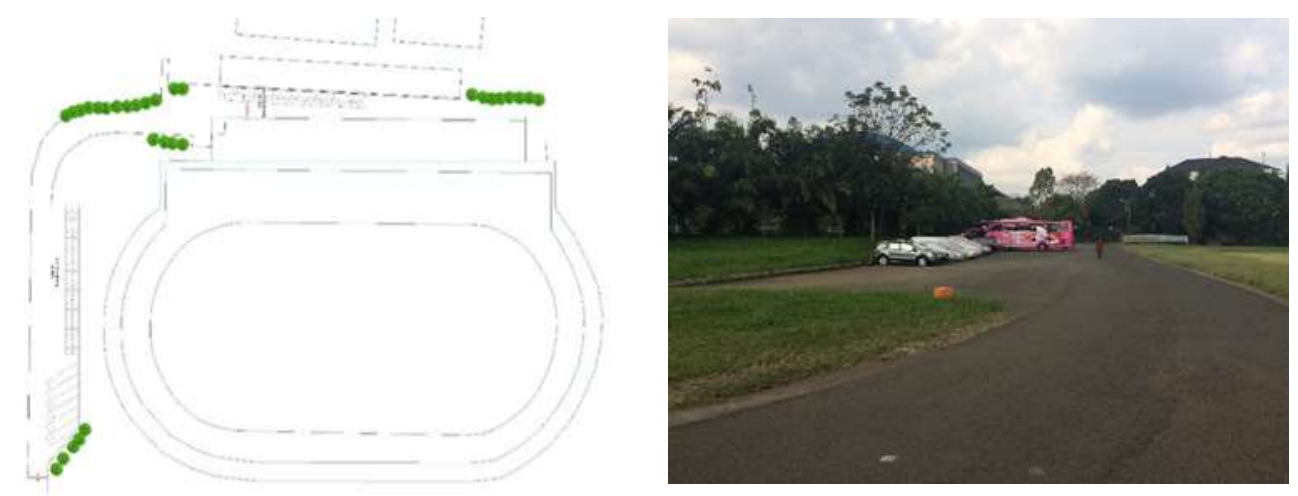

Figure. 4. Parking area of sports activities center

Parking swimming pool Arena and UPI stadium are located behind when entering the Indonesian University of Education, on this parking lot there is a parking for visitors' buses. The parking lot of the bus is required to park near the UPI stadium, and the parking area along with the swimming pool and stadium is $1068.69 \mathrm{~m}^{2}$

With these parking conditions the parking plan:

1. Four-wheeled SRP group I is $2.3 \mathrm{~m} \times 5 \mathrm{~m}$

2. Parking at the Pool \& Stadium is an on street parking or off-street parking

3. Parking patterns

- According to the $90^{\circ}$ parking angle with the provision of an effective maneuver space of $6.2 \mathrm{~m}$

- According to the parking angle of 600 (bus) with the provision of a 2-way alley lane width of $9.5 \mathrm{~m}$

From the Pool \& Stadium parking the capacity of 34 four-wheeled parking spaces with a parking area of $1068.69 \mathrm{~m}^{2}$ was obtained.

Observation phase by calculating the duration of each vehicle that enters and exits and records the identity of the vehicle. In addition, it can find out the field conditions for the implementation of parking space units, parking bans, as well as parking pattern management according to land transportation agency management standards about parking

\section{Vehicle Data Analysis}

Vehicle data is used to find out which vehicles come in and vehicles that come out with the time of each minute with the time division per hour from 06.00-16.00.

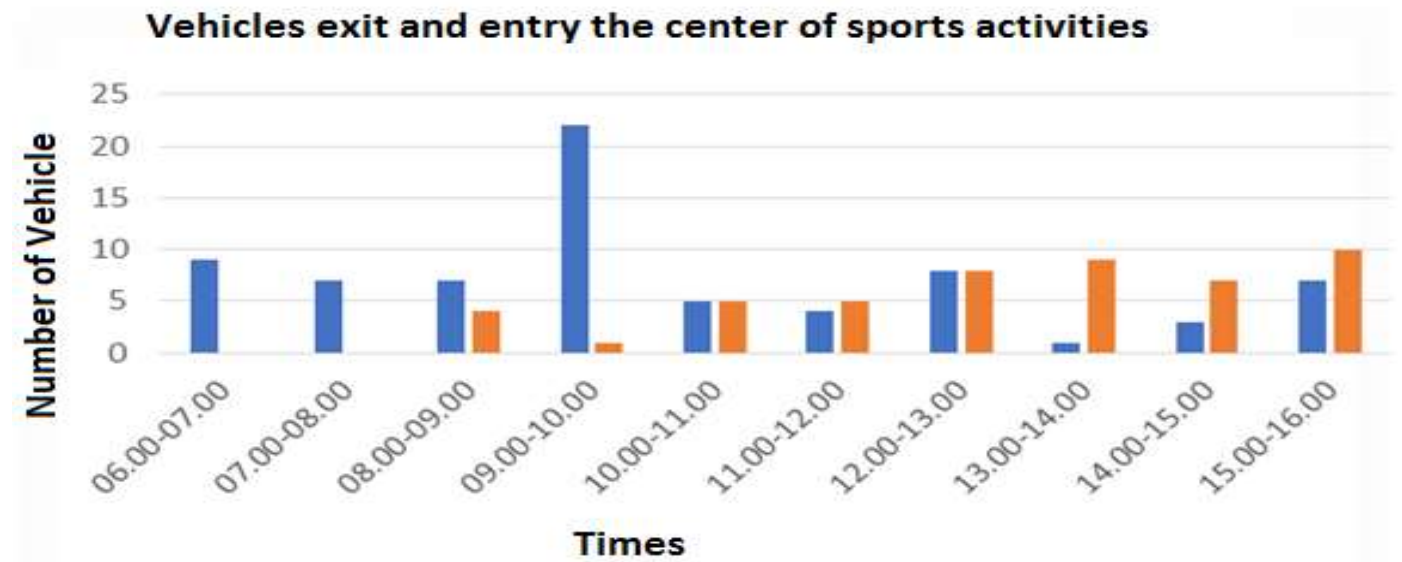

= Vehicles entry

$=$ Vehicles exit

Figure. 5. Number Vehicles exit and enter the center of sports activities 
The volume of vehicles at the center of sports activities that enter with a high volume is seen at 09:00 to 10:00, the vehicle is a routine activity for swimming training and other sports, for the largest volume of vehicles coming out is $15: 00-16: 00$ which is the completion of the activity.

\section{Analysis of vehicle parking duration}

The duration in parking is taken to determine the duration of each vehicle parked in the parking lot that has been provided, this duration is divided by hour. The duration of the highest vehicle is the average parking lot at the pool and stadium, which is $>10$ hours with the number of vehicles 24 vehicles, the duration indicates that the parking lot is used to park together with residents around the pool.

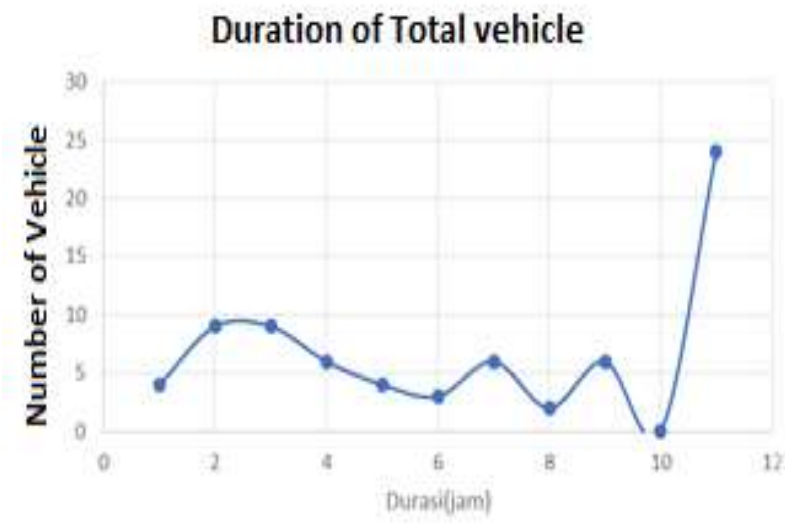

\section{Duration of Vehicle type}

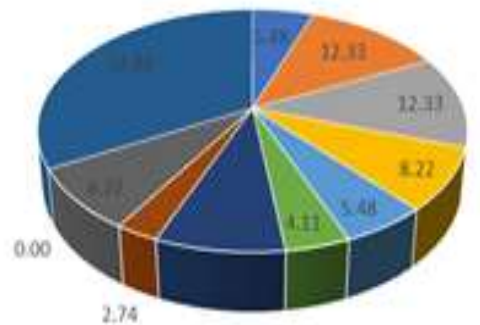

$\cdot 01 \cdot 12 \cdot 2.3+34 \cdot 45 \cdot 5 \cdot 6 \cdot 5.7 \cdot 78 \cdot 8.9 \cdot 910 \cdot 510$

Figure. 6. Characteristics of vehicle parking duration

The duration of the most vehicles is the highest average parking at the swimming pool and stadium, which is $>10$ hours with the number of vehicles 24 vehicles, the duration indicates that the parking lot is used for parking together with residents around the pool

\section{Vehicle parking accumulation}

Parking accumulation is used to find out the maximum parked vehicles in the parking lot every day, in the accumulation of parking in the Indonesian Education University taken on the highest day in the parking volume already. Accumulation is obtained from: Incoming vehicles vehicles coming out + vehicles in place.The biggest accumulation of parking is 40

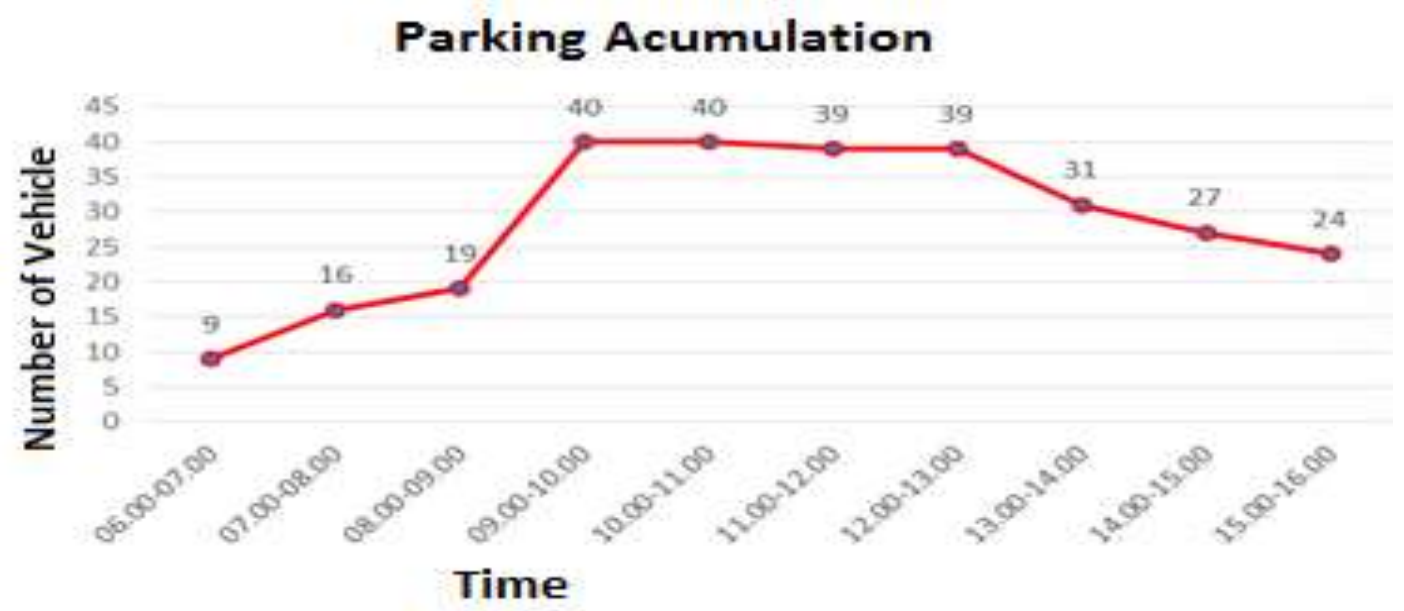

Figure. 7. Characteristics of vehicle parking accumulation 


\section{Analysis of Turnover}

Turnover is used to determine the turnover of each vehicle parked in parking space units in 1 day.

$$
\text { Turnover }=(\text { parking volume }) /(\text { available parking space })
$$

The parking volume used is the largest parking volume and parking space taken from the calculation of parking space according to SRP class I four-wheeled vehicles. Turnover $=73 / 34=2.15$ rounded up to 3 which means that in 1 parking space there are 3 times the parking change (high vehicle activity).

\section{Parking Index Analysis}

Parking index is used to determine the parking capacity presntase used.

$$
\text { Parking index }=(\text { Accumulated parking }) /(\text { Available parking area }) \times 100 \%
$$

Description $\quad:>100 \%$ (exceeding capacity)

$$
:<100 \% \text { (not exceeding capacity) }
$$

Parking Index $=40 / 34 \times 100 \%=117.65 \%$ which means it exceeds capacity of $17.65 \%$

References. References include all cited works in the text. It is the authors' responsibility to check the accuracy of references. References should follow the APA Style.

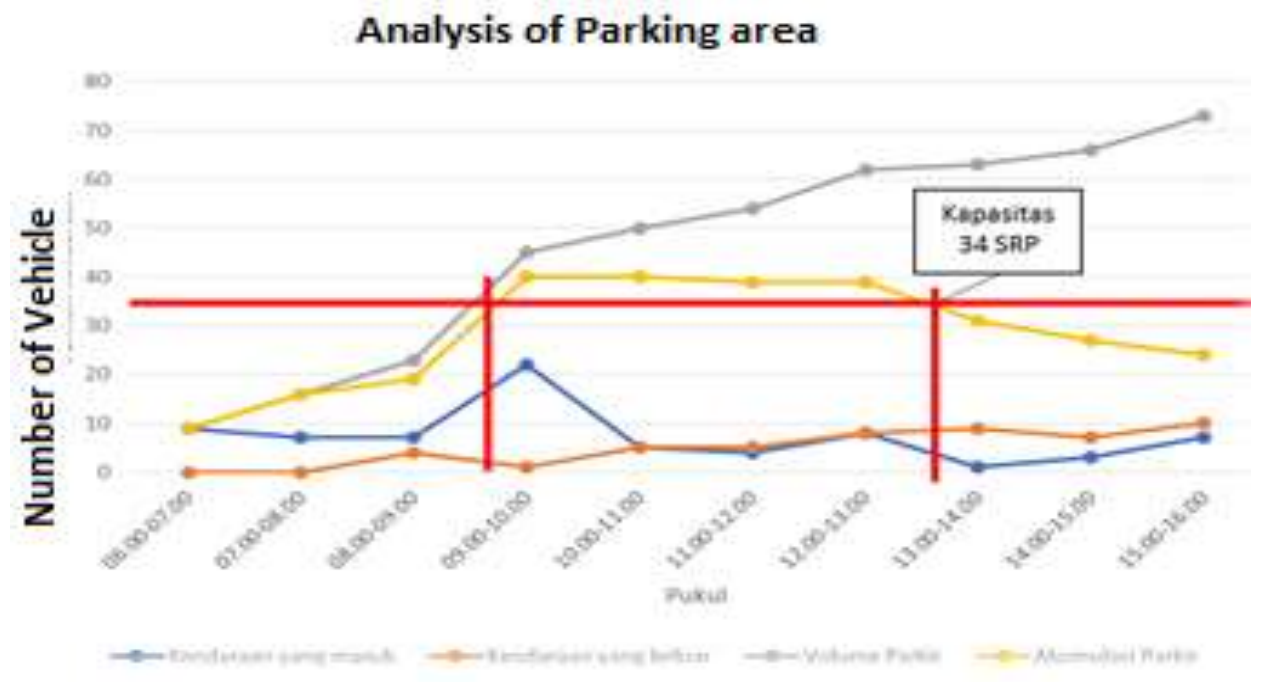

\section{Accumulation and Volume of Vehicle Parking}

From the graph above it can be seen that at 08: $30-12: 30$ (4 hours) it is always full and at 6 : 00-8: 30 (2 hours 30 minutes) and 12: 30-16: 00 (3 hours 30 minutes ) always empty.

Extensive parking area requirements

Plot number : 34 SRP

Size of vehicle class I : $: 2.3 \mathrm{~m} \times 5 \mathrm{~m}$

Parking index $\quad: 1.1764$

Parking area needed $\quad: 1.1765 \times 34 \times 2.3 \times 5=460 \mathrm{~m} 2$

\section{Analysis of Vehicle Distribution}

Parking capacity of the center of sports activities has parking capacity by 34 with user kapaistas parking spaces by 40 SRP, then parking capacity along with a pool and a stadium less than 6 SRP, not only shared parking for the stadium and the swimming pool but there is also 
parking citizen, and therefore it has to be the addition of a parking lot and parking facilities, there is a parking lot near the stadium used by UPI. On the bus parking provision of parking spaces by 6 SRP, if less then da land that can be used again. For roads to the stadium and swimming pool need to be widened again.

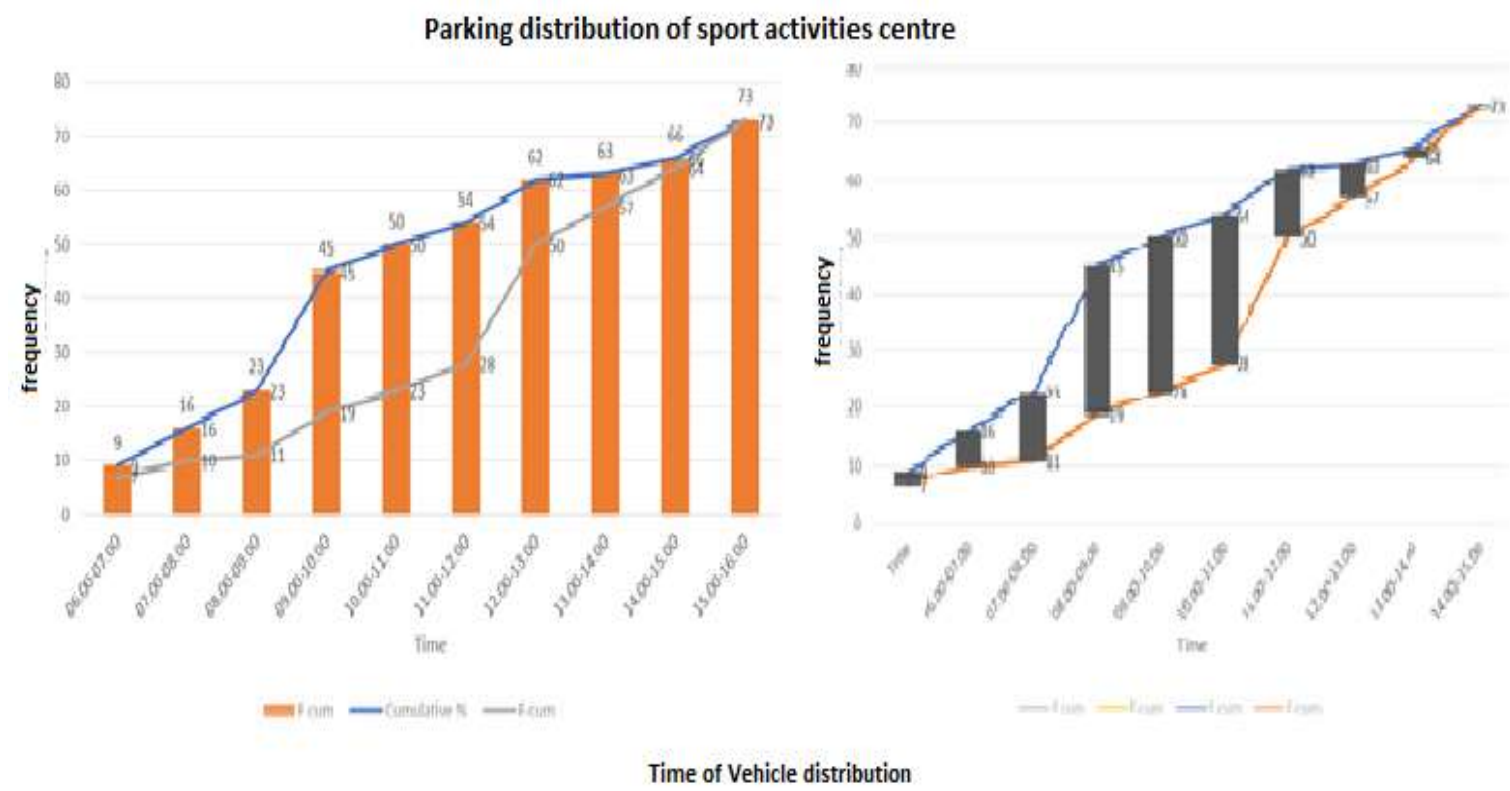

Table. 2 Parking Needs Analysis Results for predictions for the next 10 years

\begin{tabular}{cc}
\hline Parking identification & Area of Parking needed \\
\hline Number of space & $: 59 \mathrm{SRP}$ \\
Size of vehicle class I & $: 2.3 \mathrm{~m} \times 5 \mathrm{~m}$ \\
Parking Index & $: 0,949$ \\
Parking area needed & $: 0,949 \times 59 \times 2.3 \times 5=643,89 \mathrm{~m}^{2}$ \\
\hline
\end{tabular}

\section{Conclusion}

Based on the analysis of the evaluation of the parking needs of the center of sports activities in education land use shows that the parking volume with parking users exceeds the space capacity of the users of the activity center. This is because the behavior of parking users at training and competition activities at the center of sports activities increases rapidly. Central parking space for sports activities allows parking users to use outside the activity system. So that the system of sports center activities requires a parking integration system between non-commercial zones and their environment to be able to maximize parking space according to the system of activity activities in parking lots.

\section{Acknowledgement}

We thank to the head of departement of civil engineering program in Universitas Pendidikan Indonesia who has permitted researchers to conduct.

\section{References}

Akbardin,J. (2005) Evaluasi Kinerja Angkutan Umum Penumpang Wilayah Pesisir Pantai Morodemak, Jurnal Teknik Universitas Sultan Fatah. Nomor 1 September 2005

Akbardin.J (2013) Variable Relationships Estimation Of Cargo Transportation Network System To The Number Of Internal Regional Cargo Mode (Case Study Of Road Network System in Central Java Province), Jurnal Magister Teknik Sipil UMS

Akbardin, and Andri Eka Putra (2016) Analisa BOK (Biaya Operasi Kendaraan) Shuttle Service Rute Bandung-Jakarta Selatan, Jurnal Media Teknik Sipil UMM 
Akbardin, J, Khoiriyah K, Supratman O, Samsudin A, and Wibowo, FC, (2017) The Indonesian Vocational Students' Understanding on Educational Activities Center toward characteristic of user Location Accesbilities, Turkish online Journal of Educational Technology 1, 426-431

Akbardin.J, et.al (2018a) The Influence of Freight Generation Production Characteristics of the InternalRegional Zone Commodities on Sustainable Freight Transportation Highway Network System. Matec Web Conference

Akbardin.J, et.al (2018b) The Influence of Highway Transportation Infrastructure Condition Toward Commodity Production Generation for the Resilience Needs at Regional Internal Zone. E3S Web Conference

Akbardin.J, et.al (2018c) The distribution system simulation model of each zone freight transportation movement based on unlimited the gravity model algorithm . IEEE explore

Benenson, I., K. Martens, and S. Birfir. 2008. ParkAgent: An agent-based model of parking in the city.. Computers, Environment and Urban Systems 32(6): 431-439

Beunen, R., C. F. Jaarsma, and H. D. Regnerus. 2006. Evaluating the effects of parking policy measures in nature areas. Journal of Transport Geography 14(5): 376-383.

Bonsall, P., and I. Palmer. 2004. Modeling drivers' car parking behavior using data from a travel choice simulator. Transportation Research C 12(5): 321-347.

Borgers, A., A. Kemperman, L. Toll, and H. Timmermans. 2010. Measuring preferences for parking facilities in old residential areas. Proceedings of the 7th International Symposium on City Planning and Environmental Management in Asian Countries, January 9-12, Fukuoka, Japan.

CROW. 2003. Walking distances in shopping areas (in Dutch). From Parking Management to Mobility Management, Part 7. Eide, the Netherlands: Center for Research and Contract Standardization in Civil and Traffic Engineering

Departemen Perhubungan 1998, Parking Planning And Operating Guidelines

Guan, H., X. Sun, X. Liu, and L. Liu. 2005. Modeling parking behavior of better control and pricing: A case study from one of the busiest retail shopping areas in Beijing, China. Compendium of Papers of the 84th Annual Meeting of the Transportation Research Board, January 9-13, Washington DC.

Hana Karimah, Juang Akbardin, Supratman Agus 2016 Analisis Pengaruh Bangkitan Pergerakan Permukiman terhadap Kinerja Ruas Jalan Ciwastra Kota Bandung, Universitas Pendidikan Indonesia 